\title{
Investigating relationships between emotional states and self-efficacy, agency, and interest in introductory labs
}

\author{
Meghan Kinnischtzke and Emily M. Smith \\ Department of Physics, Colorado School of Mines, Golden, CO 80401
}

(Dated: August 17, 2021)

\begin{abstract}
As instructors and curriculum developers examine the role of physics lab in introductory courses, researchers are beginning to attend to students' affective experiences such as attitudes about experimentation and sense of agency. We expand on this work by exploring the relationships between emotional states and students' self-efficacy, sense of agency, and interest in the context of physics lab activities. We administered pre- and post-surveys to students in two calculus-based introductory physics courses to gauge students' perceptions of the lab activities with regard to their emotional states, self-efficacy, sense of agency, and interest. Students attend studio sessions twice per week and the lab activities are interspersed throughout the semester. The labs are primarily designed to reinforce physics concepts that were introduced to students the previous day in an interactive lecture session. Our results indicated that students' self-efficacy and sense of agency are tightly related to one another in the context of these physics labs. However, we found few clear and consistent trends between students' emotional states and their self-efficacy, sense of agency, and interest.
\end{abstract}




\section{INTRODUCTION AND BACKGROUND}

As many instructors and curriculum developers are in the process of critically examining the role of introductory physics laboratory (lab) instruction, the roles of students' affective experiences in various types of lab instruction need to be understood. Affective research about labs has focused primarily on analyses of the Colorado Learning Attitudes about Science Survey, and most studies find that focusing on experimentation skills rather than physics concepts improves students' attitudes about experimental physics [1-5]. Other studies have begun to expand to other affective experiences of students in physics labs. For example, Kalender et al. began to investigate relationships between students' sense of agency, intended to be increased in many experimentation-focused labs, and their preferences for lab activities [6]. They found that in experimentationfocused labs, students reported increasing sense of agency and their favorite lab activity was the one designed to have the most available agency. In our experience, many students have strong emotional responses to lab from their absolute favorite part of physics course to a detested component of a course. In this study, we were interested in expanding to the role of students' self-reported emotional states during lab activities that are focused on physics concepts. We focus on the relationships of emotional states to self-efficacy and sense of agency and students' general interest in the course.

Bandura proposed intricate links between self-efficacy and agency: Agency is the pursuit of goals, but to pursue a goal, a person needs to believe they can accomplish the goal, which is referred to as self-efficacy [7]. Bandura described the relationship between self-efficacy and sense of agency as: "beliefs of personal efficacy constitute the key factor of human agency. If people believe they have no power to produce results, they will not attempt to make things happen" [8]. Instructional lab settings within physics provide students with opportunities to pursue a goal of carrying out an experiment with various decisions made available, depending on instructional intent (e.g., Ref. [9]). Labs designed with greater available agency support more frequent and higher quality student decision-making in the experimentation process [10], perhaps increasing students' self-efficacy in conducting experiments due to opportunities to practice decision-making. Other factors such as gender, race, socioeconomic status and interest level can have impacts on students' self-efficacy [11], some of which have been explored in the context of introductory physics courses (e.g., Refs. [12-14]).

Bandura also argues that self-efficacy develops through four factors: enactive mastery experiences, vicarious experiences, social persuasion, and emotional states [8]. We focus on the role of students' emotional states in their self-efficacy, sense of agency, and interest in the context of physics labs. A common method of categorizing emotional states is a circumplex model of affect [15]. These

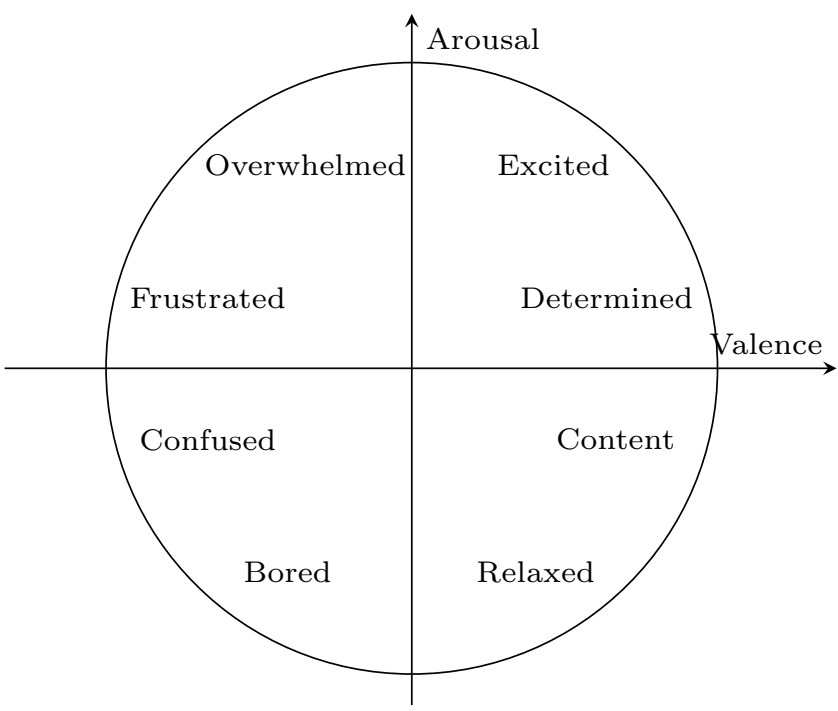

FIG. 1. Circumplex model of affect with emotional states analyzed in this paper plotted in their relative locations.

models are based on an assumption that emotional states arise from two primary physiological systems rather than a discrete set of emotions, and so emotions are mapped to a two-dimensional representation with these two systems represented as axes. A circumplex model developed by Russell [15] uses the vertical axis to represent the amount of energy that an emotion requires, typically referred to as arousal. The horizontal axis describes whether the emotion is positive or negative, referred to as valence. The model maps emotional states based on valence and arousal. Figure 1 is an example of a circumplex model for the emotional states included in this study. A number of general education studies suggest that a student's emotional state has a profound impact on their academic success [16-18].

To our knowledge, there have not been studies that explicitly focus on the role of emotional states in students' experiences in introductory physics labs, though a few studies hint at a possible mediating role of emotional state in students' self-efficacy in introductory physics $[19,20]$. Therefore, our driving research question is: In what ways are students' self-efficacy, agency, and interest related to different emotional states in a physics lab setting?

\section{METHODS}

We analyzed data from one semester of two calculusbased introductory physics courses at Colorado School of Mines: mechanics and electromagnetism (E\&M). The university is primarily an engineering school, so nearly all students are required to take both courses, with the exception of students who receive credit from AP or IB courses. Therefore, student demographics in the course are similar to those of the whole university. For this semester, the registrar data indicated that both courses had about $70 \%$ men and 30\% women. 
In these courses, students work in groups of two to four twice per week for two hour studios [21]. Due to the ongoing COVID-19 pandemic, one group member attended studio in-person while the other group members connected via Zoom. Lab activities are interspersed in studios and students complete approximately 8 lab activities throughout the semester. All activities were adapted so that students participating remotely handled simulations. The lab activities are highly structured and correspond to the lecture topic introduced the previous day. For example, in several lab activities in the E\&M course, students are provided with instructions about how to construct particular circuits using a breadboard and prompted to make a series of measurements.

To measure students' self-efficacy and sense of agency, we used items developed by Kalender et al. to measure in the context of physics labs. Items corresponding to self-efficacy were provided to us by Z. Yasemin Kalender and N. G. Holmes and items for sense of agency appear in Ref. [6], all intended for the context of physics labs. Each item has a five point scale ('strongly disagree' to 'strongly agree') and there are 11 items corresponding to self-efficacy and four to sense of agency.

We developed a set of eight emotional states (see Fig. 1) and asked students to identify the frequency (four point scale from 'never' to 'always') at which they felt each state during lab activities. To develop the set of states, we ran a pilot survey in the previous semester that included 13 states based on Nissen et al. [19, 20]. We selected eight states to represent different sectors on the circumplex model (Fig. 1) and to avoid closely overlapping states based on the pilot responses. Due to selfefficacy's link to interest within a domain [22], we also included a single interest item that prompted students to rank their level of interest in the course (five points from 'very low' to 'very high').

To score participants' self-efficacy and sense of agency data, we used Kalender et al.'s method of averaging items with equal weightings so that each participant scores from 1 (low) to 5 (high) [6]. For emotional state data, we treated each state individually on a scale from 0 (never) to 3 (always). Similarly, interest data ranged from 1 (very low) to 5 (very high). In our analyses, we treat all variables as continuous.

We administered these items as a pre-survey after the second lab activity and as a post-survey after the second to last lab activity, to avoid early/late semester confusion about various surveys that are administered in the courses. For mechanics, $29 \%$ of enrolled students (total enrollment of $\mathrm{N}=644$ ) responded to the pre-survey and $34 \%$ to the post-survey. Response rates in E\&M were lower, with $28 \%$ of enrolled students $(\mathrm{N}=462)$ responding to the pre-survey and $20 \%$ to the post-survey. All survey responses were anonymous due to IRB constraints and did not contribute to any grade in the corresponding course. Due to the anonymous nature of the data, we were unable to match pre- and post-survey responses.

Our primary research question focuses on the relation-
TABLE I. Mean scores with standard errors from pre- and post-surveys for self-efficacy, sense of agency, and interest.

\begin{tabular}{ccccc}
\hline \hline & \multicolumn{2}{c}{ Mechanics } & \multicolumn{2}{c}{ E\&M } \\
& Pre & Post & Pre & Post \\
& $(\mathrm{N}=187)$ & $(\mathrm{N}=221)$ & $(\mathrm{N}=130)$ & $(\mathrm{N}=92)$ \\
\hline Self-efficacy & $3.52(0.06)$ & $3.69(0.05)$ & $3.48(0.06)$ & $3.27(0.09)$ \\
Agency & $3.15(0.06)$ & $3.22(0.06)$ & $2.95(0.08)$ & $2.65(0.10)$ \\
Interest & $3.23(0.07)$ & $3.21(0.06)$ & $3.16(0.09)$ & $3.06(0.12)$ \\
\hline \hline
\end{tabular}

ship between students' emotional states during lab activities and outcomes theorized to depend on those states such as self-efficacy, agency, and interest in this domain. Therefore, we performed two analyses using multiple linear regression to begin to probe these relationships: (1) individually predicting each of the outcomes using only the emotional state data and (2) exploring the relationships between all constructs by predicting self-efficacy outcomes based on emotional states, agency, and interest. We selected the models presented in this paper prior to analyzing the data to specifically test the role of emotional states in students' experiences.

\section{RESULTS}

Table I provides descriptive statistics for self-efficacy, agency, and interest across both courses for the preand post-surveys. In mechanics, mean scores for selfefficacy and sense of agency increased, however, both mean scores decreased in E\&M. Due to the anonymous survey responses, we are uncertain whether these differences are due to different populations of students within the courses responding to pre- and post-surveys but suspect similar selection effects occurred in both courses. However, mean scores for students in E\&M are lower than that of mechanics, suggesting different student experiences in the two courses.

Figures 2 and 3 show the frequency at which students reported experiencing the emotional states during lab activities in mechanics and E\&M, respectively. Overall, students reported relatively high frequencies of feeling determined and confused and low frequencies of feeling excited, relaxed, and bored.

\section{A. Analysis I: Relationships with emotional states}

To test relationships between students' emotional states and self-efficacy, agency, and interest (referred to as outcomes), we individually explored the relationship of the emotional states with each of the outcomes.

Table II shows students' self-efficacy scores (possible range of 1 to 5 ) predicted by each of the eight emotional states (possible range of 0 to 3). Several emotional states consistently trend as predictors of increased self-efficacy including excitement, determination, and contentment, all of which are positive valence states on the circumplex model. Only confusion consistently trended toward decreased self-efficacy across all administrations of the sur- 


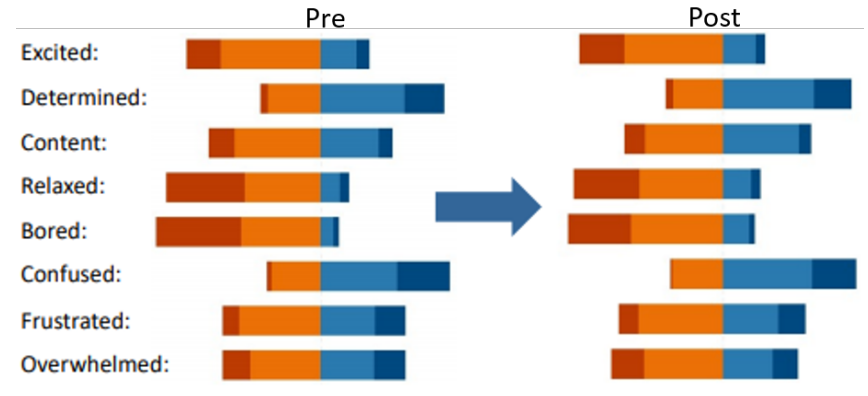

FIG. 2. Emotional state data for the mechanics course. Red (left most) corresponds to never experiencing the emotional state and dark blue (right most) represents a response of almost always experiencing the emotional state.

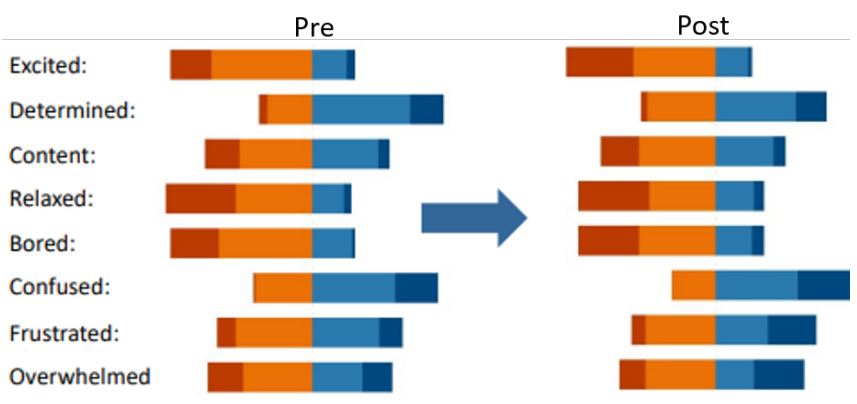

FIG. 3. Emotional state data for the E\&M course. Red (left most) corresponds to never experiencing the emotional state and dark blue (right most) represents a response of almost always experiencing the emotional state.

vey. However, only determined and confused emotional states appear to be consistently predictive of self-efficacy when considering the frequencies of students' self-reports of each emotional state shown in Figs. 2 and 3.

In Table III, students' sense of agency (possible range of 1 to 5) is predicted by each of the emotional states. There were few clear trends across all administrations of the survey. Mechanics students tended to indicate that excitement and determination may correspond to sense

TABLE II. Self-efficacy predicted by emotional states.

\begin{tabular}{lllll}
\hline \hline & \multicolumn{2}{c}{ Mechanics } & \multicolumn{2}{c}{ E\&M } \\
& Pre & Post & Pre & $\begin{array}{l}\text { Post } \\
\text { Predictor }\end{array}$ \\
$(\mathrm{N}=187)$ & $(\mathrm{N}=221)$ & $(\mathrm{N}=130)$ & $(\mathrm{N}=92)$ \\
\hline (Intercept) & $3.3(0.2)^{* * *}$ & $3.5(0.2)^{* * *}$ & $3.0(0.3)^{* * *}$ & $3.0(0.4)^{* * *}$ \\
Excited & $0.3(0.1)$ & $0.1(0.1)$ & $0.1(0.1)$ & $0.1(0.1)$ \\
Determined & $0.3(0.1)^{* * *}$ & $0.1(0.1)$ & $0.2(0.1)$ & $0.2(0.1)$ \\
Content & $0.1(0.1)$ & $0.2(0.1)^{* *}$ & $0.2(0.1)^{* *}$ & $0.2(0.2)$ \\
Relaxed & $0.1(0.1)$ & $0.1(0.1)$ & $0.1(0.1)$ & $-0.1(0.1)$ \\
Bored & $0.0(0.1)$ & $0.0(0.1)$ & $0.1(0.1)$ & $0.1(0.1)$ \\
Confused & $-0.2(0.1)^{* *}$ & $-0.3(0.1)^{* * *}$ & $-0.1(0.1)$ & $-0.1(0.2)$ \\
Frustrated & $0.0(0.1)$ & $0.1(0.1)$ & $-0.2(0.1)^{* *}$ & $-0.2(0.1)$ \\
Overwhelmed & $-0.1(0.1)$ & $0.1(0.1)$ & $0.1(0.1)$ & $-0.2(0.1)$ \\
\hline \hline
\end{tabular}

${ }^{*} \mathrm{p}<0.05 ;{ }^{* *} \mathrm{p}<0.01 ;{ }^{* * *} \mathrm{p}<0.001$
TABLE III. Sense of agency predicted by emotional states.

\begin{tabular}{|c|c|c|c|c|}
\hline \multirow[b]{2}{*}{ Predictor } & \multicolumn{2}{|c|}{ Mechanics } & \multicolumn{2}{|l|}{ E\&M } \\
\hline & $\begin{array}{l}\text { Pre } \\
(\mathrm{N}=187)\end{array}$ & $\begin{array}{l}\text { Post } \\
(\mathrm{N}=221)\end{array}$ & $\begin{array}{l}\text { Pre } \\
(N=130)\end{array}$ & $\begin{array}{l}\text { Post } \\
(\mathrm{N}=92)\end{array}$ \\
\hline (Intercept) & $2.7(0.3)^{* * *}$ & $2.8(0.3)^{* * *}$ & $2.5(0.5)^{* * *}$ & $2.9(0.6)^{* * *}$ \\
\hline Excited & $0.1(0.1)$ & $0.2(0.1)^{*}$ & $0.1(0.1)$ & $0.1(0.2)$ \\
\hline Determined & $0.3(0.1)^{* *}$ & $0.1(0.1)$ & $-0.1(0.1)$ & $0.1(0.2)$ \\
\hline Content & $0.1(0.1)$ & $0.1(0.1)$ & $0.3(0.1)^{*}$ & $0.1(0.2)$ \\
\hline Relaxed & $0.1(0.1)$ & $0.1(0.1)$ & $0.1(0.1)$ & $0.0(0.2)$ \\
\hline Bored & $-0.1(0.1)$ & $0.0(0.1)$ & $-0.1(0.1)$ & $-0.2(0.1)$ \\
\hline Confused & $-0.1(0.1)$ & $-0.2(0.1)$ & $0.0(0.2)$ & $0.1(0.2)$ \\
\hline Frustrated & $0.0(0.1)$ & $0.1(0.1)$ & $-0.2(0.1)^{*}$ & $-0.1(0.2)$ \\
\hline Overwhelmed & $0.1(0.1)$ & $0.1(0.1)$ & $0.1(0.1)$ & $-0.1(0.2)$ \\
\hline
\end{tabular}

TABLE IV. Interest predicted by emotional states.

\begin{tabular}{|c|c|c|c|c|}
\hline \multirow[b]{2}{*}{ Predictor } & \multicolumn{2}{|c|}{ Mechanics } & \multicolumn{2}{|l|}{ E\&M } \\
\hline & $\begin{array}{l}\text { Pre } \\
(\mathrm{N}=187)\end{array}$ & $\begin{array}{l}\text { Post } \\
(\mathrm{N}=221)\end{array}$ & $\begin{array}{l}\text { Pre } \\
(\mathrm{N}=130)\end{array}$ & $\begin{array}{l}\text { Post } \\
(\mathrm{N}=92)\end{array}$ \\
\hline (Intercept) & $2.5(0.3)^{* * *}$ & $3.0(0.3)^{* * *}$ & $2.3(0.5)^{* * *}$ & $2.4(0.6)^{* * *}$ \\
\hline Excited & $0.4(0.1)^{* * *}$ & $0.2(0.1)$ & $0.4(0.1)^{* *}$ & $0.5(0.2)^{* *}$ \\
\hline Determined & $0.3(0.1)^{* *}$ & $0.1(0.1)$ & $0.3(0.1)^{*}$ & $0.2(0.2)$ \\
\hline Content & $0.1(0.1)$ & $0.1(0.1)$ & $0.1(0.1)$ & $0.3(0.2)$ \\
\hline Relaxed & $0.0(0.1)$ & $0.1(0.1)$ & $0.1(0.1)$ & $-0.2(0.2)$ \\
\hline Bored & $-0.1(0.1)$ & $-0.2(0.1)$ & $-0.1(0.1)$ & $-0.1(0.1)$ \\
\hline Confused & $-0.1(0.1)$ & $-0.1(0.1)$ & $0.1(0.2)$ & $0.2(0.2)$ \\
\hline Frustrated & $-0.1(0.1)$ & $-0.1(0.1)$ & $0.1(0.1)$ & $-0.3(0.2)$ \\
\hline Overwhelmed & $0.0(0.1)$ & $0.0(0.1)$ & $-0.3(0.1)^{*}$ & $0.0(0.2)$ \\
\hline
\end{tabular}

of agency, of which both emotional states have both positive valence and arousal. For E\&M students, however, contentment (contributing to increased sense of agency) and frustration (decreased sense of agency) are the most dominant emotional states in the model. The nearly null effects across the emotional states for all administrations of the survey perhaps best indicates that emotional state has a minimal impact on students' sense of agency, especially when compared to the self-efficacy results in Table II. However, students who experience positive emotional states may be more likely to feel that they are in control of their lab.

Finally, in Table IV students' course interest (possible range of 1 to 5 ) is predicted by each of the eight emotional states. Positive arousal and valence emotional states (excited and determined) tend to be the best predictors of interest. Excitement is a consistently large predictor of interest in both courses and survey administrations. We suspect that the relationship between excitement and interest may result because students who are more interested in course material are likely to be positively engaged in course tasks. For the negative valence emotional states, only bored had a consistent negative trend for predicting interest, however, frustrated may also correspond to less course interest. 
TABLE V. Self-efficacy predicted by sense of agency, interest, and emotional states.

\begin{tabular}{|c|c|c|c|c|}
\hline \multirow[b]{2}{*}{ Predictor } & \multicolumn{2}{|c|}{ Mechanics } & \multicolumn{2}{|l|}{ E\&M } \\
\hline & $\begin{array}{l}\text { Pre } \\
(\mathrm{N}=187)\end{array}$ & $\begin{array}{l}\text { Post } \\
(\mathrm{N}=221)\end{array}$ & $\begin{array}{l}\text { Pre } \\
(\mathrm{N}=130)\end{array}$ & $\begin{array}{l}\text { Post } \\
(\mathrm{N}=92)\end{array}$ \\
\hline (Intercept) & $2.1(0.3)^{* *}$ & $2.1(0.2)^{* *}$ & $2.2(0.4)^{* *}$ & $1.7(0.4)^{* * *}$ \\
\hline Agency & $0.3(0.1)^{* * *}$ & $0.4(0.04)^{* * *}$ & $0.3(0.1)^{* * *}$ & $0.4(0.1)^{* * *}$ \\
\hline Interest & $0.1(0.1)$ & $0.1(0.04)^{* * *}$ & $0.1(0.1)$ & $0.1(0.1)$ \\
\hline Excited & $-0.1(0.1)$ & $0.0(0.1)$ & $0.0(0.1)$ & $0.1(0.1)$ \\
\hline Determined & $0.2(0.1)^{* *}$ & $0.1(0.1)$ & $0.2(0.03)^{*}$ & $0.2(0.1)$ \\
\hline Content & $0.1(0.1)$ & $0.1(0.1)^{*}$ & $0.1(0.1)$ & $0.2(0.1)$ \\
\hline Relaxed & $0.1(0.1)$ & $0.0(0.1)$ & $0.1(0.1)$ & $0.0(0.1)$ \\
\hline Bored & $0.1(0.1)$ & $0.0(0.1)$ & $0.1(0.1)$ & $0.2(0.1)$ \\
\hline Confused & $-0.2(0.1)^{*}$ & $-0.2(0.1)^{* *}$ & $-0.1(0.1)$ & $-0.1(0.1)$ \\
\hline Frustrated & $0.0(0.1)$ & $0.1(0.1)$ & $-0.2(0.1)^{* *}$ & $0.1(0.1)$ \\
\hline Overwhelmed & $-0.1(0.1)$ & $0.0(0.1)$ & $0.1(0.1)$ & $-0.1(0.1)$ \\
\hline
\end{tabular}

\section{B. Analysis II: Connections between constructs}

Due to the intricate relationships between self-efficacy, agency, interest, and emotional states, we also wanted to explore the relative effects of emotional states in students' self-efficacy when including sense of agency and interest. Table V shows the outcome of self-efficacy with predictors of all constructs explored in this study. Agency is a consistent and strong predictor of self-efficacy, suggesting the relationship between self-efficacy and sense of agency that was initially proposed by Bandura prominently appears in this context. Students' reported interest in the course trends positive with higher self-efficacy, however, the relative effect of sense of agency is three to four times larger than that of interest. Emotional states, similar to interest, tend to have small to null effects compared to sense of agency in predicting students' self-efficacy. Trends in emotional states indicate that feelings of confusion may consistently correspond to less self-efficacy and feelings of determination and contentment may correspond to elevated self-efficacy. Interestingly, all of these emotional states tend to be middle levels of arousal on the circumplex model. Other emotional states have inconsistent or null trends when predicting self-efficacy with sense of agency and interest included as predictors.

\section{DISCUSSION}

In this study, we explored the relationships between emotional states and students' self-efficacy, sense of agency, and interest in the context of physics lab activities that are highly structured and intended to reinforce lectures. We found self-efficacy and sense of agency to be tightly related to one another, supporting findings in prior studies on links between self-efficacy and agency also exist for the domain of physics labs. Students in mechanics on average reported an increase in self-efficacy and sense of agency over the semester, however, students in E\&M reported decreases. Our results show few consistent trends in the contribution of emotional states to self- efficacy. However, slight trends indicate that determination and contentment may correspond to increased selfefficacy and that confusion with decreased self-efficacy.

Several limitations exist to our findings. Due to IRB restrictions, we were unable to collect individually identifying information about students and, therefore, could not match pre- and post-surveys for participating students. We suspect substantial overlap between students who participated in pre- and post-surveys, however, do not know the extent. Similarly, our response rates represent only about a quarter to a third of the students in the courses, which may introduce selection effects for which we are unable to account. Additionally, the use of surveys for obtaining emotional state data may oversimplify the complexity of student experiences during lab activities. Students' emotional states vary depending on the tasks and timing of the semester. For example, students who enjoy working with their group may experience contentment when chatting with group members but then may experience frustration when working with lab equipment. Therefore, the context of lab activities is not fine-grained to understand the complexity of student experiences during labs. Lastly, treating all constructs as continuous variables may mask underlying trends and be contributing to null results, especially for emotional state data.

From an instructional standpoint, the decrease in selfefficacy and sense of agency in the E\&M course is concerning, especially because the mechanics course demonstrates slight gains. We suspect this difference between the courses may be due to explicit exercises in the mechanics course that requires students to openly discuss their group dynamics and improving collaborative work. With several items on the self-efficacy survey pertaining to confidence in building lab group dynamics, explicit discussion of group dynamics could positively affect students' reported self-efficacy. These exercises are not done in the E\&M course. Alternatively, there may be larger differences in the structure of the lab activities for the courses such as the number of decisions available to students. We did not directly compare instruction in the two course but in the future may pursue analyses such as those in Refs. [9, 10].

The students were engaged in lab activities that were highly structured and reinforced concepts introduced in lectures. However, the conversations about the role of labs in introductory physics courses is pushing toward using experimentation-focused labs (e.g., Ref. [23]). As labs are shifted to engage students in more frequent decisionmaking and experimentation, considering students' selfefficacy and sense of agency throughout development of lab activities may be a productive avenue to investigate shifts in lab instruction.

\section{ACKNOWLEDGMENTS}

We thank Dr. Z. Yasemin Kalender and Dr. N. G. Holmes for sharing survey items, Dr. Kalender for analysis discussion, and Dr. Holmes for manuscript feedback. 
[1] B. R. Wilcox and H. J. Lewandowski, Open-ended versus guided laboratory activities:impact on students' beliefs about experimental physics, Phys. Rev. Phys. Educ. Res. 12, 020132 (2016).

[2] B. R. Wilcox and H. J. Lewandowski, Developing skills versus reinforcing concepts in physics labs: Insight from a survey of students' beliefs about experimental physics, Phys. Rev. Phys. Educ. Res. 13, 010108 (2017).

[3] N. G. Holmes, J. Ives, and D. Bonn, The impact of targeting scientific reasoning on student attitudes about experimental physics, in Physics Education Research Conference 2014, PER Conference (Minneapolis, MN, 2014) pp. 119-122.

[4] L. E. Strubbe, J. Ives, N. G. Holmes, D. Bonn, and N. K. Sumah, Developing student attitudes in the first-year physics laboratory, in Physics Education Research Conference 2016, PER Conference (Sacramento, CA, 2016) pp. 340-343.

[5] E. M. Smith, M. M. Stein, C. Walsh, and N. G. Holmes, Direct measurement of the impact of teaching experimentation in physics labs, Phys. Rev. X 10, 011029 (2020).

[6] Z. Y. Kalender, M. M. Stein, and N. G. Holmes, Sense of agency, gender, and students' perception in open-ended physics labs, in Physics Education Research Conference 2020, PER Conference (Virtual Conference, 2020) pp. 259-265.

[7] A. Bandura, Self-efficacy mechanism in human agency, American Psychologist 37, 122 (1982).

[8] A. Bandura, Self-efficacy: The exercise of control (Worth Publishers, 1997).

[9] E. M. Smith and N. G. Holmes, Evaluating instructional labs' use of deliberate practice to teach critical thinking skills, Phys. Rev. Phys. Educ. Res. 16, 020150 (2020).

[10] N. G. Holmes, B. Keep, and C. E. Wieman, Developing scientific decision making by structuring and supporting student agency, Phys. Rev. Phys. Educ. Res. 16, 010109 (2020).

[11] T. Buchanan and N. Selmon, Race and gender differences in self-efficacy: Assessing the role of gender role attitudes and family background, Sex Roles 58, 822 (2008), pMID: 33015365 .

[12] R. Dou, E. Brewe, J. P. Zwolak, G. Potvin, E. A. Williams, and L. H. Kramer, Beyond performance metrics: Examining a decrease in students' physics selfefficacy through a social networks lens, Phys. Rev. Phys.
Educ. Res. 12, 020124 (2016).

[13] V. Sawtelle, E. Brewe, R. M. Goertzen, and L. H. Kramer, Identifying events that impact self-efficacy in physics learning, Phys. Rev. ST Phys. Educ. Res. 8, 020111 (2012).

[14] Z. Y. Kalender, E. Marshman, C. D. Schunn, T. J. NokesMalach, and C. Singh, Damage caused by women's lower self-efficacy on physics learning, Phys. Rev. Phys. Educ. Res. 16, 010118 (2020).

[15] J. Russell, A circumplex model of affect, Journal of personality and social psychology 39, 1161 (1980).

[16] C. Valiente, J. Swanson, and N. Eisenberg, Linking students' emotions and academic achievement: When and why emotions matter, Child Development Perspectives 6, 129.

[17] A. Kitsantas, A. Winsler, and F. Huie, Self-regulation and ability predictors of academic success during college: A predictive validity study, Journal of Advanced Academics 20, 42 (2008), https://doi.org/10.4219/jaa-2008867.

[18] J. Amsterlaw, K. Lagattuta, and A. Meltzoff, Young children's reasoning about the effects of emotional and physiological states on academic performance, Child development 80, 115 (2009).

[19] J. Nissen, M. R. Stetzer, and J. Shemwell, The experience sampling method: Investigating students' affective experience, in Physics Education Research Conference 2012, PER Conference, Vol. 1513 (Philadelphia, PA, 2012) pp. 294-297.

[20] J. M. Nissen and J. T. Shemwell, Gender, experience, and self-efficacy in introductory physics, Phys. Rev. Phys. Educ. Res. 12, 020105 (2016).

[21] P. B. Kohl, V. Kuo, and T. Ruskell, Documenting the conversion from traditional to studio physics formats at the colorado school of mines: Process and early results, in Physics Education Research Conference 2008, PER Conference, Vol. 1064 (Edmonton, Canada, 2008) pp. 135138.

[22] P. J. Silvia, Self-efficacy and interest: Experimental studies of optimal incompetence, Journal of Vocational Behavior 62, 10.1016/S0001-8791(02)00013-1 (2003).

[23] E. Smith and N. Holmes, Best practice for instructional labs, Nature Physics 17, 662-663 (2021). 